\title{
Erratum to: The fourth Standard Model family and the competition in Standard Model Higgs boson search at Tevatron and $\mathrm{LHC}$
}

\author{
N. Becerici Schmidt ${ }^{1, a}$, S.A. Çetin ${ }^{2, b}$, S. Iştın ${ }^{1, c}$, S. Sultansoy ${ }^{3,4, d}$ \\ ${ }^{1}$ Physics Department, Boğaziçi University, Istanbul, Turkey \\ ${ }^{2}$ Physics Department, Doğuş University, Istanbul, Turkey \\ ${ }^{3}$ Physics Division, TOBB University of Economics and Technology, Ankara, Turkey \\ ${ }^{4}$ Institute of Physics, Academy of Sciences, Baku, Azerbaijan
}

Received: 18 August 2011 / Published online: 22 October 2011

(C) Springer-Verlag / Società Italiana di Fisica 2011

Erratum to: Eur. Phys. J. C (2010) 66:119-126

DOI 10.1140/epjc/s10052-010-1238-1

After publication we discovered an error in Fig. 7. The correct figure should read as follows.

Fig. 7 Higgs branching ratios in SM-4 where fourth family fermions are assumed to be infinitely heavy

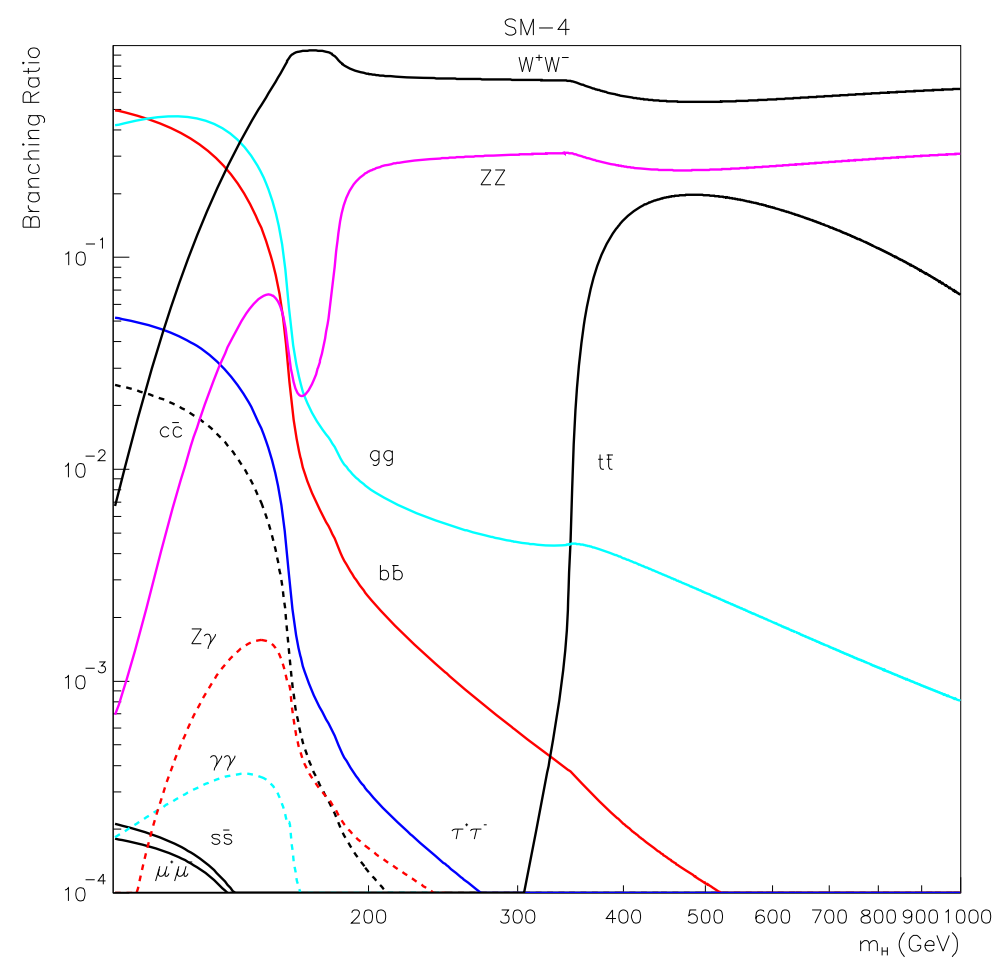

The online version of the original article can be found under doi:10.1140/epjc/s10052-010-1238-1.

a e-mail: neslihanbecerici@gmail.com

be-mail: serkant.cetin@cern.ch

c e-mail: istins@gmail.com

de-mail: ssultansoy@etu.edu.tr 